\title{
Luck, Effort and Reward in an Organisational Hierarchy
}

by

\author{
Rick Audas \\ University of New Brunswick
}

Tim Barmby

University of Newcastle upon Tyne and Institute for Labour Research, University of Essex

John Treble

University of Wales, Bangor and Institute for Labour Research, University of Essex

June 2000

\begin{abstract}
We use administrative personnel records of a large British financial sector employer to investigate how workers' behaviour responds to remuneration differences and 'luck' in the promotion system. The main methodological innovation is the use of the early part of a panel dataset to construct an individual specific measure of the importance of luck in the promotion process. The measure of luck is used to analyse workers' behaviour in the later part of the panel.

The substantive results should probably be treated with caution until confirmed by evidence from other firms and contexts. In a nutshell, we confirm that workers respond to larger remuneration spreads by working harder. They are not prepared to work so hard, though, if the promotion system operates in an unpredictable fashion.

Our evidence also bears on behavioural differences between men and women, and between workers at different levels of the hierarchy. We are unable to detect any difference between men's and women's reactions to the incentives provided by pay and promotion. The large and robust gender differences displayed in the raw data are therefore not due to incentives. We need to look elsewhere for an explanation. Similarly large and robust differences in absence behaviour between different levels of the hierarchy are actually reversed when the effect of incentives is factored out.

Acknowledgements: Barmby and Treble would like to acknowledge the support of the ESRC under grant number R000222401, and the hospitality of the Tinbergen Institute and the Free University, Amsterdam. The paper has benefited from useful comments by Richard Davies, Joseph Lanfranchi, Gauthier Lanot, Stephen Nickell and Ian Walker. Thanks are also due to seminar audiences at Newcastle upon Tyne, Tilburg, Free University Amsterdam, Groningen, Keele, ILR Essex, Leicester, York and session participants at the 1998 RES held at Warwick where earlier versions of the paper were presented. All errors are, of course, ours.
\end{abstract}

Address for correspondence: Tim Barmby, Department of Economics, University of Newcastle upon Tyne, Newcastle upon Tyne NE1 7RU, T.A.Barmby@ncl.ac.uk 


\title{
Luck, Effort and Reward in an Organisational Hierarchy
}

\author{
by \\ Rick Audas \\ University of New Brunswick \\ Tim Barmby \\ University of Newcastle upon Tyne and Institute for Labour Research, University of Essex \\ John Treble \\ University of Wales, Bangor and Institute for Labour Research, University of Essex
}

\section{Introduction}

In this paper we investigate empirically the respective roles of incentives and good fortune in a hierarchical promotion system.

The functions of hierarchy and associated promotion systems have been the subject of much debate in personnel economics in recent years. A number of papers published in the mid80's dealt with theoretical aspects of hierarchy. These include McLeod and Malcomson(1988) who model the hierarchy as a pure sorting mechanism. In the McLeod/Malcomson view, the purpose of promotion systems is to match workers to jobs in an internal labour market. The difficulty is that the ability of workers is not known, but the system can be optimally structured by offering a sequence of wage-effort pairs which elicit this information. Workers signal their ability by means of effort supply. High effort means: "I am sufficiently able to fill a more demanding job". The structure of the hierarchy ensures that the rewards to a promotion are sufficient to give high ability workers an incentive to seek them, while being too small to make misrepresentation by low ability workers worthwhile.

An alternative view is offered by the well-known tournament model. Here the purpose of the hierarchy is to provide incentives for effort among workers whose abilities may be identical (Lazear and Rosen(1981)). Large rewards at the top of the hierarchy are necessary to maintain incentives throughout the structure. Without them, the option value of successive promotions would diminish (Rosen(1986)). 
So to what extent do internal labour markets provide incentives for harder work, and to what extent do they sort by ability? This is not an easy question to answer since observed performance is affected by both ability and effort. There is also likely to be substantial element of luck involved. The McLeod/Malcomson model downplays the issues surrounding luck. Ability is assumed to be fixed, and workers are subjected to a series of tests which they can either work hard to pass or not ${ }^{1}$. The key point is derived from the Spence (1973) signalling model where it is less costly in terms of effort for an able worker to pass a given hurdle than it is for a less able worker.

On the other hand the Lazear/Rosen model downplays the ability issue and concentrates on effort incentives. One advantage of a tournament is that it eliminates the effect of random shocks common to all workers, by concentrating on the performance of each relative to peers. If there are ability differences among workers, this advantage may be attenuated because a low ability worker in a contest against someone with higher ability would need to work very hard, or have lots of luck, to win. The high ability worker on the other hand could win without much effort.

Estimating effort effects thus requires that ability be controlled for. There are several ways in which this might be done: the first is to obtain extraneous information about the ability of workers, perhaps from schooling records. The inclusion of such 'human capital' measures is now a standard procedure in empirical labour economics. Often the measure is simply years of schooling, which may, of course, include all sorts of things other than ability, including prior effort and incentives to continue at school. Examination results will suffer from similar problems. If effort is important in determining performance at work, it is likely to be similarly important in determining educational success.

Second, one could use panel data in which workers are observed progressing through several promotions. Treating ability as a fixed effect, would enable identification of effort effects. This solution is infeasible with our present data set because we observe too few promotions for each individual.

\footnotetext{
${ }^{1}$ In some hierarchies, the consequence of not passing these tests are more severe than in others. Job and career loss is common in the American legal profession (O'Flaherty and Siow(1995) and in professional sports. In other professions (academia, banking), failure to be promoted often means simply that one stays on the rung of the ladder that one has reached already with, of course, the option of a career switch. Jones and Makepeace (1996) use an ordered probit model to estimates male/female promotion thresholds with a cross-section of data from a similar financial firm to ours.
} 
A third possibility is the approach that we adopt here. We treat each grade in the hierarchy as a separate 'ability' group of homogeneous workers. This is consistent with a model of promotion in which different aspects of ability are being tested at each promotion step ${ }^{2}$.

In the research reported here, we measure the impact of a promotion system on effort supply by using the absence rate as a proxy for effort. The present paper is unusual in two respects: Firstly, most of the literature that seeks to assess the impact of reward schemes on effort uses data from sports $^{3}$; secondly, our data enable us to extract information about the uncertainty in the system, and about the attitudes of workers to risk and effort. To the extent that this is a good measure the theory suggests that absence will be negatively related to pay spread. Since the empirical work rests on the idea that we are able to control for ability, we use the tournament model introduced by Lazear and Rosen(1981) as our main theoretical vehicle. The model and its implications has been the subject of much theoretical debate, and we do not intend to exposit it at length here. Many of the issues, and much of the theoretical debate surrounding the model are discussed by McLaughlin(1986). The following section introduces the main ideas used in the subsequent empirical work. Section 3 describes our data, while Section 4 describes the dynamic binary choice model used to estimate the parameters of the model. Section 5 reports the results, and Section 6 concludes the paper with a discussion and suggestions for further research.

\section{Theory}

Tournaments offer fixed prizes and are set up in such a way that the probability of winning these prizes is a positive function of effort. For firms in a perfectly competitive industry, an optimal tournament is one that generates economic profits of zero, and elicits the first best level of effort (for which the marginal social cost of effort is equal to its marginal social benefit).

Consider a tournament for promotion from level $l$ in the hierarchy to level $l+1$, and suppose initially that there are only two contestants, $i$ and $j$. Let $W_{l+1}$ represent the reward to the winner, and $W_{l}$ the reward to the loser. Then $W_{l+1}-W_{l}$ represents the prize spread. The probability that contestant $i$ wins the tournament is a function of $i$ 's own effort $\mu_{i}$, and also of

\footnotetext{
${ }^{2}$ See, for example, Bhattacharya and Guasch (1988)

${ }^{3}$ See Prendergast(1999), pp34-36.
} 
his rival $\mathrm{j}$ 's effort $\mu_{j}$. The contestants are unable to control the outcome exactly. They both may be lucky or unlucky, and the luck they experience may affect them individually or jointly. Denote the luck experienced by individual $k$ by $\varepsilon_{k}, k=i, j$, and suppose that the difference in the contestants' good or bad fortune, $\varepsilon_{j}-\varepsilon_{i}$, has CDF, $G$ with associated PDF, $g$. Then the probability that $\mathrm{i}$ wins the tournament is a function of both contestants' effort and both contestants' luck, $P\left(\mu_{i}, \mu_{j} ; \varepsilon_{i}, \varepsilon_{j}\right)$ with $\frac{\partial P}{\partial \mu_{k}}>0, k=i, j .$. Suppose too that the cost of effort to $k$ is convex in effort, and denoted $C_{k}\left(\mu_{k}\right)$ with $C^{\prime}>0$ and $C^{\prime \prime}>0$. The optimal effort supply of $k$ is then determined by:

$$
\left[W_{l+1}-W_{l}\right] \frac{\partial P}{\partial \mu_{k}}=C^{\prime}\left(\mu_{k}\right)
$$

The probability that $i$ wins in a contest against an identical opponent $j$ is

$$
\operatorname{Pr}\left(\mu_{i}+\varepsilon_{i}>\mu_{j}+\varepsilon_{j}\right)=\operatorname{Pr}\left(\mu_{i}-\mu_{j}>\varepsilon_{j}-\varepsilon_{i}\right)=G\left(\mu_{i}-\mu_{j}\right)
$$

Therefore $\frac{\partial P}{\partial \mu_{k}}=g\left(\mu_{i}-\mu_{j}\right)$. In equilibrium the effort of the competitors is the same, so that $\frac{\partial P}{\partial \mu_{k}}=g(0)$. The equilibrium effort supply for two identical individuals competing against each other is thus:

$$
\left[W_{l+1}-W_{l}\right] g(0)=C^{\prime}\left(\mu_{k}\right), k=i, j
$$

In this framework ${ }^{4}$ higher pay spreads are associated with higher effort levels through the convexity of the cost function.

\footnotetext{
${ }^{4}$ Although as Gibbs(1994) points out this empirical regularity is not a unique implication of Tournament theory. Other similar promotion based incentive mechanisms would also have this implication. One of the main ones would be if promotion within organisations was defined by the setting of performance standards, and all workers who achieved these standards were promoted. Lazear and Rosen (1981) suggest that in the context of managerial promotion measurement difficulties might hinder the construction of promotion standards.
} 
Profit maximisation with this effort supply and the competitive zero profit condition implies an optimal prize spread ${ }^{5}$. Potentially, this creates an endogeneity problem for our analysis, because we use prize spread as an explanatory variable. However, the prize spread and the measure of "importance of luck" we construct, we view as weakly exogenous because the time scale over which these quantities are determined is longer than that over which individual workers make their effort decisions.

The setting of wage spread depends on a number of parameters of the problem. In the two contestant model with risk neutral contestants and output price normalised to unity, the optimal wage spread is

$$
\Delta w^{*}=\frac{1}{g(0)}
$$

That is, the prize spread is higher, the greater the influence of luck on the outcome of the tournament. With risk averse contestants, optimal prize spread depends not only on the distribution of luck through $g(0)$, but also on the degree of risk aversion (denoted by the Arrow-Pratt measure, $S$ ), and the convexity of the cost function, $C^{\prime \prime}{ }^{6}$ :

$$
\Delta w^{*}=\frac{g(0)}{g(0)^{2}+S C^{\prime \prime} / 4}
$$

These results follow through to the more general cases with n-contestants.

$$
\Delta w^{*}=\frac{f_{n}(n)}{f_{n}(n)^{2}+S C^{\prime \prime} / 4}
$$

where $f_{n}(n)$ is the density associated with $F_{n}(n)$, the probability of finishing $n$ 'th in an $n$ person tournament ${ }^{7}$.

\footnotetext{
${ }^{5}$ For details see McLaughlin(1986).

${ }^{6}$ In addition, some formulations of the model imply that the variance of common risk, to which all contestants are subject, enters the expression. In this case, the appropriate expression for the optimal prize spread is:

$$
\Delta w^{*}=\frac{g(0)}{g(0)^{2}+S C^{\prime \prime} /\left[4\left(1+\sigma_{\eta}^{2}\right)\right]} .
$$

${ }^{7}$ We have performed simple, reduced form, estimations of equation (5) and the indications form the signs of the coefficients are that the data is consistent with this theory. Details of these estimations are available from the corresponding author on request.
} 


\section{Data}

The data are drawn from a database constructed from the personnel records of a major British financial sector firm. A fuller description of the dataset and of the characteristics of the firm's personnel policy can be found in Treble et al. (2000). The firm varies in size over the time that we observe it, but includes around 40,000 full-time employees, and 20,000 part-time employees. We have data from the personnel and payroll archives that have been maintained since 1988, referring to the firm's British operations. Our data run from January 1989 to March 1997, giving 99 monthly observations. Each observation includes an employee ID number, age, sex, marital status, number of children, ethnic origin, job code, work unit code, salary, bonus, hierarchical grade, date of entry into current spell of employment, performance rating, partial post code of home and work, and for those employees in post in March 1991, some indicators of educational attainment. From January 1992 onwards, we also have a daily record of attendance. This is coded according to the putative reason for any days not worked, so that absence which is claimed to be due to sickness can be separated from other varieties of absence (e.g. maternity and jury service, but not, unfortunately, holidays).

The firm operates a well defined internal labour market ${ }^{8}$. The organisational hierarchy is composed of 14 levels or grades. Two of these grades we ignore. They are reserved for people who are either not part of the hierarchy, or have not for some reason been assigned to a grade. Of the remaining 12 grades, we have ignored people in the lowest 3 , since these are training grades in which promotion is more geared to attainment of a standard than to demonstrated superiority over rival employees. Our analysis does not use the top 3 grades, since they are so sparsely populated, and we analyse the behaviour in the 6 grades 5 through 10, information on grade 11 being included to define the prize for people in grade 10.

Pay is comprised of a base salary plus a performance-related bonus. In the period we are examining, approximately $25 \%$ of the workforce received an annual bonus, assessed using annual appraisals both of the employees themselves and of the units to which they were assigned. Five different appraisal ratings are possible: 'Outstanding' (5) is the best, followed by 'Very Good', 'Satisfactory', 'Not Fully Effective' and 'Unsatisfactory' (1), respectively. In practice, employees rarely receive evaluations below 'Satisfactory'. At any one time there are quite a large number of employees who have no rating. This is because of a lag between a hire or promotion and the first appraisal in the new job.

\footnotetext{
${ }^{8}$ See Treble, van Gameren, Bridges and Barmby(2000).
} 
The various results reported involve three separate estimations, each of which uses a separate subset of the whole dataset.

1. The main estimation is an effort equation in which we regress the measured absence rate (as a proxy for effort) against a number of right hand side variables. The model used is a logistic mixture model incorporating a variation of Chamberlain's (1980) method of correction for bias due to correlation of the unobserved component on the observed regressors. The computational burden of this is heavy, and so we have used a randomly selected sample of 998 individuals from the set of individuals who were employed in Grades 5-10 at some time between January 1992 and December 1993. The data used refer to this sample's behaviour every month during that same period. This gives an unbalanced panel of data with $N=998$ and $T_{i} \leq 507$ for all i. A table of summary statistics is given as Appendix Table A.1.

2. The right hand side variables in the main estimation include an measure for each individual of $g(0)$, calculated from a subsidiary equation described in detail in Section 5 below. The equation models promotion as a function of a number of characteristics of individuals and their jobs. The subsidiary equation uses information for the period from April 1991 to December 1991, (i.e. prior to that used in the main estimation), in order to avoid endogeneity problems. We use the largest possible sample in order to be sure that there is sufficient information to obtain a precise estimate for each possible type of individual. However, the individuals included in the sample used for the main estimation are omitted, to avoid any possible contamination. This gives us a sample of 27758 , which, since the time window is short, is treated as a cross section. A simple logit technique is used for estimation. A table of summary statistics is given as Appendix Table A.2.

3. Finally, we use Orme's (1996) technique to check for initial conditions bias in the main panel estimation. This involves creating generalised residuals from a subsidiary estimation which are then included in the main estimation. The details are discussed in Section 4.1. This estimation can only be done using individuals who are already employed in Grades 5-10 at the start of January 92, since there are no initial conditions applying to those joining the sample 
after this. Accordingly, we use the entire cross section of 24,283 individuals employed at January 1992 b carry out the subsidiary estimation required by Orme's technique. A table of summary statistics is given as Appendix Table A.3.

Our use of the available data is thus driven by the competing claims of : the avoidance of endogeneity bias; maximal precision; and computational tractability. The main estimation uses a panel with a two year span, the start date of which is determined by the need to reserve some information for the construction of the luck variable. April 1991 is the start of recorded absence data. We use the first 9 months for the estimation of $g(0)$, and the following 2 years for the main equation.

\section{Econometric Model}

\subsection{Basic structure}

The theory outlined in Section 2 predicts that effort will be related to a number of characteristics of individuals and their work contracts. In the empirical part of the paper we treat daily absences as an indicator of effort. Accordingly, we want to model the incidence of absence. We employ a latent variable structure which we assume generates the observed binary absence event history.

Let

$$
d_{i t}=\left\{\begin{array}{l}
1 \quad \text { if } d_{i t}^{*}>0 \\
0 \quad \text { if } d_{i t}^{*} \leq 0
\end{array}\right.
$$

where

$$
d_{i t}^{*}=\beta^{\prime} x_{i t}+\gamma d_{i t-1}+\sigma u_{i}+v_{i t} ; i=1, \ldots, N ; t=1, \ldots, T_{i}
$$

According to this structure we observe the binary variable representing attendance $\left(d_{i t}=1\right)$ or attendance $\left(d_{i t}=0\right)$ at various times $t$, for $N$ individuals indexed by $i$. The attendance decision is determined for each individual by the value of the latent variable $d_{i t}^{*}$. This is assumed to be a function of a $p$-vector of observed independent variables, $x_{i t}$, and the lagged attendance 
indicator, $d_{i t-1}$. The error has a components-of-variance structure, with $u_{i}$ representing a timeinvariant, individual-specific unobserved component, and $v_{i t}$ is the remaining error. Parameter vectors $\beta, \gamma$ and $\sigma$ have conformable dimensions $p, 1$ and 1 , respectively.

Assuming that $u_{i}$ is a realisation of a random variable $u$ with PDF $h(u)$ in the population, a marginal likelihood can be formed by integrating out $u$ in the following way:

$$
\ln (\beta, \gamma)=\sum_{i=1}^{N} \ln \int_{-\infty}^{\infty} \prod_{t=2}^{T_{i}}\left[F\left(\beta^{\prime} x_{i t}+\gamma d_{i t-1}+\sigma u\right)\right]^{d_{u}}\left[1-F\left(\beta^{\prime} x_{i t}+\gamma d_{i t-1}+\sigma u\right)\right]^{1-d_{u}} h(u) d u
$$

where $\mathrm{F}$ is the CDF corresponding to $v_{i t}$. The unobserved term, $u$, is assumed to be distributed as a standard normal variate, and estimation can be performed by the SABRE software developed by Barry, Francis and Davies(1990).

\subsection{Construction of $g(0)$}

The theory outlined in Section 2 predicts that effort depends on the spread of wages between grades and also on luck. Wage spread we compute directly from the data, but measuring $g(0)$ is more difficult. In tackling this problem, we use prior information about the promotion of individuals to calculate a measure for each type on a rich menu of different individual types. Suppose, for instance, that an adequate description of individuals specifies their gender, grade and performance rating. Suppose further that promotion decisions take account of these three variables only, and luck. Then the influence of luck for each distinct type can be gauged from the residuals of a logit regression of promotion on gender, grade and performance rating. The three independent variables give $2 \times 6 \times 5=60$ different types of individual, for each of which an estimate of $g(0)$ can be computed. The specification adopted below is, of course, richer than in this illustration?

Specifically, we estimate a Logit model, in which the dependent variable describes whether or not a worker was promoted between April 1991 to December 1991. On the right hand side are
a. a set of dummy variables for grade (omitted category: Grade 5);
b. a dummy variable for gender (omitted category: Male);
c. interactions between the grade and gender dummies;

\footnotetext{
${ }^{9}$ We are grateful to Stephen Nickell for pointing out the value of as long a regressor list as possible in this context.
} 
d. a set of dummy variables for performance rating (omitted category: 'Satisfactory' or worse);

e. the employee's absence record relative to that of other employees in the same grade.

Estimation uses data for the whole population of 28756 full time workers employed at April 1991, excluding the 998 workers used to estimate the main effort equation. The period is chosen since it precedes the two-year period for which we analyse the absence data and thus obviates any possible endogeneity problem. April 1991 is the earliest date for which we have absence data.

The absence variable is constructed using the recoded absence rate, $r_{i}$, of each individual. This is the number of days absent during the 9 months to December 1991 divided by the number of contracted days. We subtract from this the mean absence rate of all the employees in the same grade, $l_{i}$, as employee $i, \overline{r_{l_{i}}}=\frac{1}{n_{l_{i}}} \sum_{i \in l_{i}} r_{i}$, to create $\Delta r_{i}=r_{i}-\overline{r_{l_{i}}}$.

Using Equation (2), we can write the probability of winning the contest for an individual with characteristics $y_{i}$ as:

$$
G\left(\Delta r_{i} ; y_{i}\right)=L\left(\psi^{\prime} y_{i}+\theta \Delta r_{i}\right)
$$

where $L$ is the logistic function. Differentiating this expression with respect to $-\Delta r_{i}$ (our measure of effort), and setting $\Delta r_{i}$ equal to zero gives our estimator for $g(0)$ :

$$
\overline{g(0)}=\frac{\partial G}{\partial \Delta r}=-\theta L^{\prime}\left(\psi^{\prime} y\right)
$$

The results of the logit estimation are given in Table 1 below. The promotion probability from Grade 6 into Grade 7 is significantly lower than from Grade 5 into Grade 6. This is because a promotion from 6 to 7 marks the qualitatively significant transition from clerical to managerial status. The probability of promotion is also low at the very top of the hierarchy. Women are overall have lower promotion probabilities than men, but these differences are concentrated in the clerical and lower managerial grades. These findings are consistent with results from the dataset reported in Treble et al. (2000), and with results from a different dataset reported by Jones and Makepeace(1996). High performance ratings improve promotion 
chances, and high absence rates reduce them, as one would expect. Rather more subtle is the significant improvement in promotion chances for unrated employees. These employees are nearly all recent promotees, and the result echoes the findings of Bridges(1999) on fast-track effects in this same dataset. The idea of a fast-track is that promotion is easier to obtain for recent promotees than for other observationally identical individuals. This may be because of missing relevant information in the model, or could be evidence of the existence of a biased contest.

\begin{tabular}{|c|c|c|}
\hline \multicolumn{3}{|c|}{ Table 1: Promotion Logit; N=27758 } \\
\hline Variable (Mean) & "Coefficient & "Standard Error \\
\hline Constant & -2.7477 & 0.0888 \\
\hline Grade6 & -0.3646 & 0.0905 \\
\hline Grade7 & -0.0034 & 0.0978 \\
\hline Grade8 & 0.0577 & 0.1059 \\
\hline Grade9 & -1.3381 & 0.1823 \\
\hline Grade10 & -0.9981 & 0.2279 \\
\hline Gender & -0.6362 & 0.0779 \\
\hline Gender*Grade6 & -0.0211 & 0.1250 \\
\hline Gender*Grade7 & 0.0541 & 0.1571 \\
\hline Gender*Grade8 & 0.3651 & 0.2356 \\
\hline Gender*Grade9 & 1.2125 & 0.4953 \\
\hline Gender*Grade10 & 0.8286 & 0.7625 \\
\hline$\Delta r$ & -6.6017 & 0.8379 \\
\hline Rate4 & 0.7939 & 0.0713 \\
\hline Rate5 & 1.0645 & 0.0866 \\
\hline Unrated & 0.5367 & 0.0845 \\
\hline \multicolumn{3}{|c|}{ Log-likelihood $=-6806.5496$} \\
\hline
\end{tabular}

However that may be, the main point of the estimation in Table 1, is to enable the computation described in Equation (11) to be done. Summary statistics of the resulting series are included in Appendix Table A.1. 


\subsection{Two technical problems}

Two potentially important technical problems arise with the econometric structure as specified. Firstly, the existence of a lagged endogenous variable in the specification gives rise to an initial conditions problem ${ }^{10}$ which can cause bias in panel estimators. Secondly, the unobserved component $u$ is not necessarily independent of observed regressors. To the extent that $u$ reflects motivation, morbidity or other long-term factors influencing work performance then we can a priori expect it to exhibit dependence with certain included regressors, in particular with grade. Once again, this induces a potential inconsistency in the estimator. We discuss these problems in turn.

\subsubsection{Initial conditions problem}

The initial conditions problem is unlikely to be serious since such biases are known to be most serious in short panels and our data has a large time dimension ( $\mathrm{T}=507)$. For completeness, we use the method suggested by Orme (1996) to check for potential inconsistency. Orme's method begins by assuming that the initial condition, which in our case is the choice of absence at time $t=1$, can be modelled as

$$
d_{i 1}^{*}=\lambda^{\prime} y_{i}+\eta_{i}
$$

where $y_{i}$ is a vector containing current and/or pre-sample values of regressors. The event $d_{i 1}=1$ is the same as the event $d_{i 1}^{*}>0$. Assuming bivariate normality between $u_{i}$ in $(8)$ and $\eta_{i}$, Orme shows that $E\left(u_{i} \mid d_{i 1}\right) \equiv e_{i 1}=\left(2 d_{i 1}-1\right) \frac{\phi\left(\lambda^{\prime} y_{i}\right)}{\Phi\left(\left\{2 d_{i 1}-1\right\} \lambda^{\prime} y_{i}\right)}$ which is a Probit generalised error. Thus $\sigma u_{i}=\sigma \rho e_{i 1}+v_{i}$ where $v_{i}$ is an error term uncorrelated with $d_{i 1}$. Substituting in (8) suggests an estimation procedure where the $e_{i 1}$ are replaced by their predictions $\overline{e_{i 1}}$ and added to the regressor set. The equation used to generate the estimated generalised residuals included grade, gender, age and interactions of age with grade and gender. Age is entered nonlinearly, and acts as identifying information. The result of the estimation is shown in Table 2.

\footnotetext{
${ }^{10}$ See Hsiao(1989).
} 


\begin{tabular}{|c|c|c|}
\hline \multicolumn{3}{|c|}{$\begin{array}{l}\text { Table 2: Initial Conditions Probit } \\
\qquad \mathrm{N}=\mathbf{2 4 , 2 8 3}\end{array}$} \\
\hline Variable & $\overline{\text { Coefficent }}$ & Ptandard Error \\
\hline Const & -1.2728 & 0.1237 \\
\hline Grade & -0.1083 & 0.0190 \\
\hline Gender & 0.2595 & 0.0372 \\
\hline Age & -0.0180 & 0.0126 \\
\hline $\mathrm{Age}^{2}$ & -0.0002 & 0.0002 \\
\hline Gender*Age & -0.0120 & 0.0044 \\
\hline Grade*Age & 0.0016 & 0.0020 \\
\hline \multicolumn{3}{|c|}{ Log-likelihood $=-3854.68$} \\
\hline
\end{tabular}

\subsubsection{Dependency of unobserved component on observed regressors}

To allow for the likely dependency of the unobserved component on the observed regressors we follow the procedure suggested by Chamberlain(1980). The unobserved term, $u$, in Equation (8) captures the effect of individual-specific unmeasured factors such as motivation and morbidity on the probability of absence. Chamberlain's method models the correlation between $u$ and the observed regressors by allowing the individual-specific effect to depend linearly on the values of the regressors during the whole period of the data.

Let $z_{i t}$ be a $q$-dimensional subvector of the included regressors, $x_{i t}$. Then write $u_{i}$ as:

$$
u_{i}=\sum_{t=1}^{T_{i}} \alpha_{t}^{\prime} z_{i t}+\eta_{i}
$$

where $\alpha_{t}$ is a conformable $q \times 1$ parameter vector. It is important to note here that the summations are over $t$, and so that future values of regressors are allowed to be informative about the occurrence of a current event. 
Since $T$ is large, using Equation (13) unmodified would involve estimating a large number of extra parameters. Greater parsimony can be achieved by assuming $\alpha$ to be time invariant and factoring it out of the above expression to give

$$
u_{i}=\alpha T \frac{\sum_{t=1}^{T_{i}} z_{i t}}{T}+\eta_{i}
$$

where $\alpha$ is now a scalar, and the expression has been rewritten as an expression in the means of the $z_{i t}$.

Chamberlain's method, employed in this way, can be interpreted as allowing the mean of the distribution of the unobserved component to shift by a linear combination of the means (taken over time) of the variables it is believed to be correlated with. In the estimates reported we included a single variable, the grades occupied by each individual from time to time during the two year window of our data, as the $z_{i t}$, thus allowing the distribution to shift by a linear multiple of mean grade.

The empirical procedure can be interpreted in the following way: For any given individual, mean grade over time can be interpreted, ceteris paribus, as an indicator of longterm unobserved determinants of absence behaviour, such as motivation, morbidity or household structure. Incorporating mean grade as a regressor shifts the mean of the distribution of the unobserved term for each individual.

\section{Results}

The estimates of the mixture model, Equation (8), are reported in Table 3. The data used are an unbalanced panel of 998 employees observed monthly over 2 years from January 1992. The specification adopted is greatly influenced by a perceived need for parsimony, in order to handle the computational burdens imposed by the estimation procedure. The dependent variable is the absence rate, $r_{i t}$, which is included on the right hand side with a one month lag. Other right hand side variables are: 
Table 3: Estimates of Logistic Mixture Model for Effort (Absence Histories)

\begin{tabular}{|c|c|c|c|c|}
\hline \multirow[b]{2}{*}{ Variable } & \multicolumn{2}{|c|}{ Specification I } & \multicolumn{2}{|c|}{ Specification II } \\
\hline & "Coefficient & "Standard Error & " Coefficient & "Standard Error \\
\hline Constant & -3.4104 & 0.3423 & -3.3972 & 0.3612 \\
\hline Lag absence & 4.8213 & 0.0242 & 4.8211 & 0.0242 \\
\hline Payspread & -0.2026 & 0.0941 & -0.2033 & 0.0940 \\
\hline$\overline{\overline{g(0)}}$ & -0.3702 & 0.1560 & -0.4083 & 0.1927 \\
\hline Gender & 0.3016 & 0.0615 & 0.2578 & 0.1989 \\
\hline$\overline{\text { Gender* }} \overline{g(0)}$ & & & 0.1143 & 0.3165 \\
\hline Gender*Payspread & & & -0.0119 & 0.1501 \\
\hline Lower Management & 0.1298 & 0.0967 & 0.1288 & 0.0958 \\
\hline Higher Management & 0.5209 & 0.2159 & 0.5105 & 0.2169 \\
\hline Mean Grade & -0.2214 & 0.0592 & -0.2200 & 0.0596 \\
\hline$\overline{e_{1}}$ & 0.1338 & 0.5003 & 0.1533 & 0.5154 \\
\hline$\sigma$ (scale parameter) & 0.7520 & 0.0199 & 0.7516 & 0.0198 \\
\hline Log-likelihood & \multicolumn{2}{|c|}{-34784.9800} & \multicolumn{2}{|c|}{-34784.8905} \\
\hline
\end{tabular}

a. the two variables of interest: payspread (scaled by a factor of $10^{-4}$ ) and luck $(\overline{g(0)})$;

b. a dummy for gender;

c. in Specification II, interactions between the variables of interest and gender;

d. a simplified dummy structure for grade consisting of a lower management indicator (Grade 7 or $8=1$ ) and a higher management indicator (Grades 9 and above $=1$ ). The omitted category is clerical Grades 5 and 6. All these represent the grade occupied by the employee in January 1992, or at the date of entry into the firm, whichever is earlier;

e. the Chamberlain correction term (mean grade) described in Section 4.3.2; and

f. the Orme generalised residual $\left(\bar{e}_{1}\right)$ described in Section 4.3.1. 
The table also reports estimates of the scale parameter $(\sigma)$ in the mixture model.

The estimated Orme generalised residual, $\bar{e}_{1}$, is insignificant in the equation suggesting that the length of the panel is sufficiently long to render any initial conditions bias negligible.

Turning to the substantive results, note that since the dependent variable is a measure of absence, a negative coefficient on a right hand side variable implies that an increase in the value of that variable increases effort supply. Thus increasing payspread increases effort, as does increasing $g(0)$. In the latter case, since $g(0)$ is the height of a density function, we conclude that the evidence implies that the less important luck is in determining promotion decisions, the greater the effort that workers will put in to secure a promotion. Both these results are consistent with a tournament view of the world. The latter result, in particular, is as far as we know new, and has the important interpretation that capricious decision making in the context of promotion has quantifiable incentive effects, over and above its implications for misallocated resources.

We find support for the two main empirical regularities predicted by tournament theory; but we also find that there are differing effects between the genders. It is now a commonplace observation that absence rates are higher among women than among men ${ }^{11}$. This is confirmed in this data, but our results also show that women do not react differently from men in their responses to he incentives provided by the reward structure and the promotion system. Neither interaction term has a statistically significant effect. This suggests that the differences between men and women's absence rates (or, more speculatively, work effort) are not generated by differential responses to incentives, but by selection effects.

A contrasting conclusion is reached with respect to seniority in the hierarchy. Table 3 shows that higher management actually are more likely to be absent than other grades, when the incentive effects of payspread and luck are controlled for. Again, this seems like an important observation: senior managers' behaviour in this organisation, according to this evidence is actually very heavily influenced by incentive systems of pay and promotion, so much so that the raw differential in absence behaviour is reversed when the effect of incentives is controlled for.

\footnotetext{
${ }^{11}$ See, for instance, Barmby et al.(1999)
} 


\section{Conclusion and future research}

We see the main contribution of the present paper as methodological. We have taken the ordinary administrative records of a large firm and developed a way of using them to cast light on various aspects of incentive schemes and selection. The main methodological innovation is the use of the early part of a panel dataset to construct an individual specific measure of the importance of luck in the promotion process.

The substantive results of our investigation are also of considerable interest, but should probably be treated with caution until confirmed by evidence from other firms and contexts. In a nutshell, they are that men's and women's reactions to the incentives provided by pay and promotion are indistinguishable. The large and robust gender differences displayed in raw data are therefore not due to incentives. We need to look elsewhere for an explanation. Similarly large and robust differences in absence behaviour between different levels of the hierarchy are actually reversed when the effect of incentives is factored out. This poses a rather different, but equally intriguing challenge to future research. 


\section{References}

Barmby, T.A., Ercolani, M., and Treble J.G.(1999) "Sickness Absence in Great Britain:New Quarterly and Annual Series from the GHS and LFS 1971-1997 Labour Market Trend August pp 405-415.

Barry, J., Francis, B. and Davies, R.: "SABRE: Software for the Analysis of Binary

Recurrent Events" (1990) Centre for Applied Statistics, Lancaster University.

Bhattacharaya, S. and Guasch, J. L.: "Heterogeneity, Tournaments, and Hierarchies" Journal of Political Economy (1988) Vol 96:4 pp867-81.

Bridges, S. (1999) "Promotion and Fast-tracking: An Empirical Analysis using Firm Micro

Data" mimeo, Department of Economics, University of Newcastle upon Tyne

Chamberlain, G.: “Analysis of Covariance with Qualitative Data” Review of Economic Studies (1980) Vol 67 pp225-38.

Gibbs, M.: "Testing Tournaments? An Appraisal of the Theory and the Evidence" Labor Law Review. (1994) Spring 1994.

Green, J. R. and Stokey, N. L.: “A Comparison of Tournaments and Contracts” Journal of Political Economy (1983) Vol 91 pp349-64.

Hsiao, C.: Analysis of Panel Data , (1989) Cambridge University Press.

Jones, D. R. and Makepeace, G. H. "Equal Worth, Equal Opportunities: Pay and Promotion in an Internal Labour Market" Economic Journal (1996) Vol 106 pp 401-9.

Lazear, E. and Rosen, S.: "Rank Order Tournaments as Optimum Labor Contracts” Journal of Political Economy (1981) Vol 89 pp841-64.

Lazear, E. and Rosen, S.: "Male-Female Wage Differentials in Job Ladders" Journal of Labor Economics (1981) Vol 8:(2) S106-23.

Lazear, E.: Personnel Economics, (1995) MIT Press

McLaughlin, K. J.: "Aspects of Tournament Models: A Survey" Research in Labor Economics (1988) Vol 9 pp 225-256

McLeod, B. and Malcomson, J.: "Reputation and Hierarchy in Dynamic Models of Employment" Journal of Political Economy (1988) Vol 96(4) 832-854

O'Flaherty, B. and Siow, A.: "Up-or-out Rules in the Market for Lawyers" Journal of Labor Economics, Vol 13:(4), October 1995, pp 709-735

Orme, C.: "The Initial Conditions Problem and Two-Step Estimation in Discrete Panel

Data Models", (1997) mimeo, School of Economic Studies, University of Manchester.

Spence, M.: "Job market Signalling" Quarterly Journal of Economics (1973) Vol 87 pp 355-74 
Treble J., van Gameren E., Bridges S. and Barmby T.: "The Internal Economics of the

Firm: Further Evidence from Personnel Data" (1999) mimeo, Department of Economics,

University of Newcastle upon Tyne

\section{Appendix: Summary Statistics}

\begin{tabular}{|c|c|c|c|c|c|c|c|c|}
\hline \multicolumn{9}{|c|}{$\begin{array}{l}\text { Table A.1: Summary Statistics for sample used in main estimation, } \\
\qquad N=998 ; T=507\end{array}$} \\
\hline Grade & $\begin{array}{c}\text { Number } \\
\text { (Jan } \\
\text { 1992) }\end{array}$ & $\begin{array}{c}\text { Absence } \\
\text { Rate }\end{array}$ & $\begin{array}{c}\text { Mean } \\
\text { Pay } \\
(£)\end{array}$ & $\begin{array}{c}\text { Mean } \\
\text { Bonus } \\
(£)\end{array}$ & $\begin{array}{c}\text { Mean } \\
\text { Promotion } \\
\text { Rate }\end{array}$ & $\begin{array}{c}\text { Proportion } \\
\text { Female }\end{array}$ & $\begin{array}{l}\text { Mean } \\
\text { Age }\end{array}$ & $\begin{array}{l}\text { Predicted } \\
g(0)\end{array}$ \\
\hline 5 & $\begin{array}{c}388 \\
(38.8 \%)\end{array}$ & $3.56 \%$ & 11879 & 2.54 & $14.95 \%$ & $76.29 \%$ & 30.92 & 0.4602 \\
\hline 6 & $\begin{array}{c}259 \\
(25.9 \%)\end{array}$ & $3.36 \%$ & 14715 & 32.20 & $13.90 \%$ & $57.53 \%$ & 35.15 & 0.3947 \\
\hline 7 & $\begin{array}{c}190 \\
(19.0 \%)\end{array}$ & $2.21 \%$ & 18604 & 625.37 & $10.00 \%$ & $32.11 \%$ & 34.92 & 0.4120 \\
\hline 8 & $\begin{array}{c}92 \\
(9.2 \%)\end{array}$ & $1.74 \%$ & 24749 & 892.87 & $18.48 \%$ & $16.30 \%$ & 38.75 & 0.4808 \\
\hline 9 & $\begin{array}{c}53 \\
(5.3 \%)\end{array}$ & $1.46 \%$ & 36628 & 2219.2 & $7.55 \%$ & $9.43 \%$ & 41.47 & 0.1567 \\
\hline 10 & $\begin{array}{c}16 \\
(1.6 \%)\end{array}$ & $0.56 \%$ & 47721 & 4215.6 & $0.00 \%$ & $0.00 \%$ & 46.66 & 0.2166 \\
\hline
\end{tabular}




\begin{tabular}{|c|c|c|c|c|c|}
\hline \multicolumn{6}{|c|}{$\begin{array}{l}\text { Table A.2: Summary } \mathrm{St} \\
\text { estimation, } \mathrm{N}=27,758\end{array}$} \\
\hline Grade & $\begin{array}{l}\text { Proportion } \\
\text { of Sample }\end{array}$ & $\begin{array}{c}\text { Proportion } \\
\text { Female }\end{array}$ & $\begin{array}{c}\text { Proportion } \\
\text { Rated } 4\end{array}$ & $\begin{array}{c}\text { Proportion } \\
\text { Rated } 5\end{array}$ & $\begin{array}{c}\text { Proportion } \\
\text { Unrated }\end{array}$ \\
\hline 5 & $38.04 \%$ & $77.79 \%$ & $44.09 \%$ & $19.98 \%$ & $19.82 \%$ \\
\hline 6 & $24.93 \%$ & $55.87 \%$ & $36.06 \%$ & $29.24 \%$ & $22.71 \%$ \\
\hline 7 & $19.66 \%$ & $29.20 \%$ & $12.88 \%$ & $0.48 \%$ & $10.03 \%$ \\
\hline 8 & $9.45 \%$ & $13.92 \%$ & $21.43 \%$ & $0.80 \%$ & $7.51 \%$ \\
\hline 9 & $5.65 \%$ & $7.21 \%$ & $30.06 \%$ & $1.34 \%$ & $12.76 \%$ \\
\hline 10 & $2.27 \%$ & $6.66 \%$ & $38.35 \%$ & $3.49 \%$ & $15.06 \%$ \\
\hline
\end{tabular}

Table A.3: Summary Statistics for sample used in subsidiary initial conditions Probit estimation, $\mathrm{N}=\mathbf{2 4 , 2 8 3}$

\begin{tabular}{||c|c|c|c|c||}
\hline \hline Grade & $\begin{array}{c}\text { Proportion } \\
\text { of total }\end{array}$ & $\begin{array}{c}\text { Proportion } \\
\text { female }\end{array}$ & $\begin{array}{c}\text { Age } \\
\text { (years) }\end{array}$ & $\begin{array}{c}\text { Mean rate } \\
\text { of absence }\end{array}$ \\
5 & $38.23 \%$ & $76.76 \%$ & 33.19 & $5.50 \%$ \\
6 & $26.69 \%$ & $56.52 \%$ & 37.19 & $3.55 \%$ \\
7 & $19.16 \%$ & $28.80 \%$ & 37.57 & $2.69 \%$ \\
8 & $8.93 \%$ & $13.38 \%$ & 41.00 & $2.12 \%$ \\
9 & $5.35 \%$ & $6.86 \%$ & 43.06 & $1.08 \%$ \\
10 & $1.65 \%$ & $4.75 \%$ & 45.06 & $1.50 \%$ \\
\hline
\end{tabular}

